\title{
Belize: a new psychiatric service revisited
}

\author{
C. Walsh, L. Ward, J. O'Neill-Byrne, K. O'Neill-Byme and J. L. Herzberg
}

In 1990 a UK psychiatrist and community psychiatric nurse (CPN) went to Belize, in Central America, to set up a comprehenstve mental health service, based on community clinics staffed by psychiatric nurse practitioners. This work was completed by 1992. In 1994 two medical students visited Belize for eight weeks to review the new mental health service.

\section{The study}

The students visited Belize in October and November 1994. They spent the first week in Belize City, where the largest clinic is based, and then visited six other clinics run by psychiatric nurse practitioners (PNPs) across the country. The students observed a typical week in the clinic and carried out interviews. The data collected was compared to that obtained in a previous study (O'Neill-Byrne \& O'Neill-Byrne, 1994).

\section{Data collection}

All clinical notes of patients attending clinics from October 1993 to September 1994 were retrieved and data on attendance, age and gender of patients, diagnosis classified according to DSMIII-R (American Psychiatric Association, 1987) and medication, classified according to the British National Formulary (BNF; British Medical Association \& Royal Pharmaceutical Society of Great Britain, 1993), was obtained. A questionnaire was given to all patients seen and language barriers were overcome by using PNPs as translators. Semi-structured interviews were held with the PNPs, the psychiatrists and soclal workers on the team. The Minister of Health for Belize and the Principal Nursing Officer were also interviewed.

\section{Findings}

The structure of the service

The main out-patient clinic for the country was still based in Belize City and six other clinics served the rest of Belize. The mental hospital was located at Rock View, 22 miles west of Belize City amid swamp and mangrove. Two Belizian born psychiatrists have been appointed to work fulltime and $a$ third is in training. The psychiatrists are mainly based in Belize City but visit regional clinics at three-monthly intervals. They are also scheduled to visit the mental hospital and other health facilities. Fifteen PNPs have now been trained but there are no plans to employ any others. However, six PNPs are all based in district clinics as well as Belize City, Rock View and one in the School of Nursing. In the districts, the nurses prescribe drugs to both acute and chronic patients. Most nurses consult the psychiatrist over the telephone for advice on new patient treatment and any other difficult cases but the psychiatrists are not consulted for every drug prescription. Nurses also have the power to admit patients to hospital as required.

\section{Drugs}

Despite the problems with drug supplies in 1990 91 , when only $33 \%$ of the country's needs of depot medication were met, few problems were apparent on review. However, a wider varlety of drugs were available for private patients and the use of lithium was confined to a few mainly private patients. Blood levels were not routinely performed for carbamazepine. Electroconvulstve therapy was not available.

\section{The facilitles}

Rock View Mental Hospital was felt to be in a bad state of disrepair. Heavy rains caused flooding in the wards and the fragle walls are often breached by acutely psychotic patients. Rain also causes the road from the main highway to be closed. preventing visits from psychiatrists and isolating the staff based there. There are some occupational therapy sessions available. Each psychiatrist visits weekly and a general practitioner attends to medical problems each week but the nursing staff would have welcomed more psychiatric input.

\section{The clinics}

A total of 774 new patients and 4652 total attendances were recorded nationally from October 1993 to September 1994. The following data is obtained from the Belize City clinic. Fortyone per cent of patients were diagnosed as 
suffering from schizophrenia and $22 \%$ suffered from a major depressive disorder, $4 \%$ had a bipolar affective disorder and $9 \%$ an unspecifled psychosis. Organic diagnoses accounted for $5 \%$ of patients seen and included learning disability, dementias and epilepsy. Anxiety disorders were the primary diagnosis in approximately $5 \%$ of patients and $13 \%$ of patients seen did not have a psychiatric disorder. The therapeutic outcome for new patients was prescription of medication in $35.5 \%$, counselling in $61.5 \%$ and admission $3 \%$. Depot injection was often given by social workers at the patient's house.

\section{Questionnaire results}

A total of 58 questionnaires were distributed to new patients attending clinics and there was $100 \%$ response rate. The ethnicity of attenders mirrored the ethnic patchwork of Belize. Most patients attended for a consultation and not surprisingly, the group that had received the highest number of contacts was the depot injection group. Most patients only had to travel short distances to their nearest clinic. Referrals by family members accounted for $41 \%$ of referrals, self-referrals $22 \%$ and medical referrals $10 \%$. Patients had been referred by teachers, the police, a priest and even a village healer. For those receiving medication the supply had improved dramatically from 1990 to 1991 . The questionnaire suggested a high level of satisfaction by consumers of the service.

\section{Comment}

The main strengths of the service are that there are clinics in all districts of the country and each has at least one full-time PNP and is visited at regular intervals by a psychiatrist. All clinics reported an increase in uptake of services since 1990 and the data for the Belize City Clinic shows a stable pattern of use since 1990-91. The proportion of new psychotic cases has fallen and there seems to be greater awareness about mental health issues in general, with attendance at the clinics not being seen as stigmatising. Patients missing depot appointments are actively sought out, making missed injections a rarity. The PNPs appeared well trained in nearly all areas of mental health care and were competent and committed in their roles as diagnosticians, therapists and educators in the community. These findings concur with a study showing the high concordance rates between doctors and other health professionals in reaching working diagnoses in a community mental health service for the elderly (Collighan et al, 1993). The PNPs were at ease with prescribing medication with support from psychiatrists, but there was no legal provision for nurse prescribing and several nurse practitioners voiced their concern about who would be liable if any problems occurred. These factors would be pertinent if nurse prescribing is introduced in the UK. The availability of drugs throughout the country had improved markedly.

There are some apparent weaknesses in the service. In-patient facilities remain poor and a Mental Health Act written in the 1930s is still in use. The PNPs have a wide ranging role and many felt that they had been inadequately trained in child psychiatry. Time for continuing professional development was lacking. The future development of the mental health service was also an area of concern as its presence means that mental health is less of a political priority than hitherto. However, the service does not appear to have been adversely affected by the withdrawal of outside aid. We hope that the further development of the service occurs in a planned way and not as a 'knee jerk' reaction to crisis situations, as is the case in some Western countries with more highly developed services! It is hoped that the continuing contribution of the service will result in attitudes towards mental lliness in Belize continuing to improve over time.

\section{Acknowledgements}

The authors wish to thank Mr E. Campos and the staff of the Belizian Health Service. CW and LW were given financial assistance by The Enid Linder Foundation. The Rayne Foundation. The Anderson Scholarship, UMDS, the National Westminster Bank, The British Medical and Dental Students Trust, The Convocation Trust and the Mental Health Foundation.

\section{References}

AMERICAN PSYCHATRIC Assochtion (1987) Diagnostic and Statistical Manual of Mental Disorders (3rd edn, revised) (DSM-III-R). Washington, DC: APA.

Brmsh MEdical Association \& Royal PHarmaceutical SOCIETY OF GREAT BRTAN (1993) British National Formulary. No. 26. Bath: Bath Press.

Colughan G.. MACDONALD, A. HERABERG, J., et al (1993) An evaluation of the multidisciplinary approach to psychiatric diagnosis in elderly people. British Medical Journal, S08, 821-824.

O'NEILL-BYRNE, J. \& O'NEHL-BYRNE, K. (1994) Development psychiatry in Belize. Psychiatric Bullettr, 18, 241-242.

Claire Walsh, Medical Student, UMDS; Louise Ward, Medical Student, UMDS; Joseph O"NeillByrne, Community Psychiatric Nurse, Oxdeas Mental Health Trust, Katrina O'Neill-Byrne, Consultant Psychiatrist, Oxdeas Mental Health Trust, and "Joe Herzberg, Senior Lecturer in Psychiatry, Division of Psychiatry and Psychology. United Medical and Dental School of Guy's and St. Thomas' Hospital, St. Thomas Street, London SE1

"Correspondence 